\title{
Pharmacokinetics, biodistribution and metabolism of a novel selective androgen receptor modulator designed for prostate cancer imaging
}

\author{
JUN YANG ${ }^{1}$, ZENGRU WU ${ }^{1}$, DI WU ${ }^{1}$, MICHAEL V. DARBY ${ }^{2}$, SEOUNG SOO HONG ${ }^{3,4}$, \\ DUANE D. MILLER ${ }^{3,4}$ and JAMES T. DALTON ${ }^{1,4}$ \\ Divisions of ${ }^{1}$ Pharmaceutics and ${ }^{2}$ Medicinal Chemistry, College of Pharmacy, The Ohio State University, \\ Columbus, OH 43210; ${ }^{3}$ Department of Pharmaceutical Sciences, College of Pharmacy, \\ The University of Tennessee; ${ }^{4} \mathrm{GTx}$, Inc., Memphis, TN 38163, USA
}

Received August 4, 2009; Accepted September 14, 2009

DOI: 10.3892/ijo_00000492

\begin{abstract}
Knowledge of the presence and extent of disease plays a major role in clinical management of prostate cancer, as it provides meaningful information as to which therapy to choose and who might benefit from this therapy. The wide expression of androgen receptor (AR) in primary and metastatic prostate tumors offers a cellular target for receptormediated imaging of prostate cancer. In our previous study, a non-steroidal AR ligand, S-26 [S-3-(4-fluorophenoxy)-2hydroxy-2-methyl-N-(4-cyano-3-iodophenyl)-propionamide] showed promising in vitro pharmacological properties as an AR-mediated imaging agent, with high AR binding affinity and AR specificity. The overall goal of this study was to characterize the in vivo metabolic and biodistribution profile of S-26 in rats. Non-compartmental pharmacokinetic analysis of S-26 in rat plasma showed that clearance (CL), volume of distribution $\left(\mathrm{Vd}_{\mathrm{ss}}\right)$, and half-life $\left(\mathrm{T}_{1 / 2}\right)$ of $\mathrm{S}$-26 were $0.30 \pm 0.07 \mathrm{l} / \mathrm{h} / \mathrm{kg}, 1.44 \pm 0.33 \mathrm{l} / \mathrm{kg}$, and $4 \mathrm{~h}$, respectively, after intravenous (i.v.) administration. Dose proportionality (1, 10 and $30 \mathrm{mg} / \mathrm{kg}$ ) studies suggested that the pharmacokinetics of S-26 are dose-independent. The plasma concentrations of all
\end{abstract}

Correspondence to: Dr James T. Dalton, GTx, Inc., 3 North Dunlap Street, Memphis, TN 38163, USA

E-mail: jdalton@gtxinc.com

Abbreviations: AR, androgen receptor; DHT, dihydrotestosterone; $\mathrm{T}$, testosterone; SHBG, sex hormone binding globulin; PEG 300, polyethylene glycol 300; Ki, dissociation equilibrium constant of the inhibitor; HPLC, high-performance liquid chromatography; LCMS, liquid chromatography-mass spectrometry; MS/MS, tandem mass spectrometry; GI tract, gastrointestinal tract; CL, clearance; AUC, area under the concentration-time curve; $\mathrm{T}_{1 / 2}$, elimination half-life; $\mathrm{Vd}_{\mathrm{ss}}$, volume of distribution at equilibrium; DES, diethylstilbrestil; ID/g, injected dose per gram of tissue

Key words: pharmacokinetics, biodistribution, metabolism, androgen receptor, prostate cancer
3 doses were further simultaneously fitted with a two-compartmental model and the results were similar to those obtained from non-compartmental analysis. Biodistribution studies using ${ }^{125}$ I-labeled S-26 indicated that it did not specifically target AR-rich tissue (e.g. prostate). A substantial amount of radioactivity recovered from thyroid gland indicated the release of free iodine. In metabolism studies, unchanged S-26 and its metabolites were detected in rat urine and fecal samples. Oxidation, de-iodination, hydrolysis, and sulfate conjugation were the major metabolic pathways of S-26 in rats, with deiodination representing a unique metabolic pathway of S-26 among other selective androgen receptor modulators. In conclusion, the extensive plasma clearance and de-iodination of S-26 likely contribute to its lack of AR tissue selectivity in vivo. Future studies using metabolically stable ligands with less lipophilicity and higher AR binding affinity may represent a promising and rational approach for AR-mediated imaging.

\section{Introduction}

Prostate cancer is the most commonly diagnosed cancer and remains the second leading cause of death from cancer in American men (1). Procedures for reliable and accurate staging of prostate cancer are essential in the management of prostate cancer. Androgen receptor (AR) is an important intracellular receptor, which mediates the pharmacologic effects of androgens and is involved in the progression of prostate cancer. $\mathrm{AR}$ is expressed in all stages of prostate cancer evolution, including prostatic intraepithelial neoplasia $(2)$, primary $(3,4)$ and metastatic disease $(5,6)$, both before and after androgen ablation therapy. Even androgen-independent tumors express the AR (2). Metastatic prostate tumors expressing AR regardless of their sensitivity to hormonal therapy offer a cellular target for receptor-mediated imaging or treatment of advanced prostate cancer.

Chemicals that modulate AR activity can be divided into four classes based on their structure (steroidal and nonsteroidal) and function (androgenic and antiandrogenic). Non-steroidal antiandrogens, a major interest for the treatment 
of 'androgen-dependent' prostate cancer, have been used clinically for years. Over the past several years, we determined many of the physicochemical and structural requirements for high affinity AR binding by non-steroidal ligands $(7,8)$. Much of our research efforts have focused on characterization of the in vivo pharmacologic activity and tissue selectivity of aryl propionamide selective androgen receptor modulators (SARMs) in animal models of androgen-dependent disease (9-12). We completed extensive studies on the molecular and preclinical pharmacology of these compounds, advancing them from high affinity but metabolically labile ligands (13) to tissue-selective drugs with promising in vivo pharmacologic activity $(9,10,12,14-17)$. These studies on the structureactivity relationships for AR binding and activation provide important information for rationally modifying the structures of non-steroidal ligand to obtain novel compounds for AR mediated imaging of prostate cancer (18). Our previous studies showed that non-steroidal AR ligands incorporating iodine in either the A ring or $\mathrm{B}$ ring of the aryl propionamide pharmacophore retain high binding affinity to the AR (18-21). In our previous report, S-3-(4-fluorophenoxy)-2-hydroxy-2-methyl$\mathrm{N}$-(4-cyano-3-iodo-phenyl)-propionamide (referred to as S-26 hereafter as in ref. 18) was shown to exhibit favorable properties for further development as an imaging agent for prostate cancer, i.e., high-AR binding affinity of $3.3 \mathrm{nM}$ (which is similar to testosterone), high specificity (does not cross-react with other members of the steroid hormone receptor family) and lack of binding to SHBG, a plasma protein that binds steroids with high affinity (18). S-26 (Fig. 1) incorporates an iodine group at the meta-position of the A aromatic ring, which provides the opportunity to introduce varying isotopes of iodine for research, therapeutic and diagnostic purposes. Iodine-125 offers a good radiotracer for imaging research, whereas iodine-123 could be clinically used for diagnosis and iodine-131 could be used for receptor-mediated radiation therapy. Reported herein are the in vivo evaluations and characterization of S-26 as a potential AR mediated imaging agent. We first determined the pharmacokinetic parameters of S-26 and then synthesized ${ }^{125}$ I-labeled S-26 for in vivo biodistribution studies in rats. As a whole, these studies provide important new information regarding the metabolic and physicochemical factors that govern AR-mediated accumulation of the aryl propionamide SARMs and suggest structural modifications to improve their potential for prostate cancer imaging.

\section{Materials and methods}

Chemicals and reagents. 3-(4-fluorophenoxy)-2-hydroxy-2methyl-N-(4-cyano-3-iodo-phenyl)-propionamide (S-26), its trimethyltin precursor, and an internal standard (Fig. 1) were synthesized and characterized in our laboratories as previously described $(7,18,20,21)$. The purities of synthesized compounds were confirmed by NMR, elemental analysis and mass spectrometry. $\mathrm{Na}^{125} \mathrm{I}$ was obtained from PerkinElmer (Life Sciences, Boston, MA). HPLC grade acetonitrile, water and ethyl acetate were purchased from Fisher Scientific Company (Fair Lawn, NJ). Ethyl alcohol (USP grade) was purchased from AAPER Alcohol and Chemical Company (Shelbyville, KY). All other chemicals were purchased from Sigma Chemical Company (St. Louis, MO).
Animals. Male Sprague-Dawley rats, purchased from Harlan Biosciences (Indianapolis, IN), were kept on a 12-h light/dark cycle in temperature and humidity controlled rooms. Animals had access to food and water ad libitum. All animal studies were reviewed and approved by the Institutional Animal Care and Use Committee at The Ohio State University.

Pharmacokinetic studies. Male Sprague-Dawley rats weighing 195-238 g were used for pharmacokinetic studies. A catheter was implanted in the right jugular vein of each rat $24 \mathrm{~h}$ prior to dosing. Animals $(n=15)$ were divided into 3 groups. The pharmacokinetics of S-26 were determined after an intravenous dose of 1 or 10 or $30 \mathrm{mg} / \mathrm{kg}$ via the jugular vein. Dosing solutions were prepared by dissolving S-26 in a vehicle containing DMSO (5\%, v/v) in PEG 300. Doses were delivered in a volume of $500 \mu \mathrm{l}$, and the jugular vein catheter was flushed three times with total of $500 \mu 1$ of saline. Blood samples were collected prior to the dose and at 5, 10, 20, 40, $60,120,240,480,720,1080$ and 1440 min after drug administration. Blood samples were immediately centrifuged at $3,000 \mathrm{~g}$ for $10 \mathrm{~min}$. The plasma fraction of each sample was transferred to a clean Eppendorf tube and stored at $-20^{\circ} \mathrm{C}$ until analysis.

HPLC-UV analysis. HPLC analytical methods to determine the plasma concentration of S-26 were developed and validated. An aliquot (100 $\mu \mathrm{l})$ of each plasma sample was spiked with $20 \mu \mathrm{l}$ of an internal standard (a structural analog of S-26, $75 \mu \mathrm{g} / \mathrm{ml}$ final concentration) and mixed well with $1 \mathrm{ml}$ of acetonitrile. After centrifugation at $12,000 \mathrm{x} \mathrm{g}, 4^{\circ} \mathrm{C}$ for $5 \mathrm{~min}$, the supernatant was collected and evaporated. The residues were reconstituted in $150 \mu \mathrm{l}$ of mobile phase and an aliquot of $100 \mu \mathrm{l}$ was used for HPLC analysis. The separation of S-26 and internal standard was carried out using an isocratic mobile phase (acetonitrile/ $\mathrm{H}_{2} \mathrm{O}: 50 / 50, \mathrm{v} / \mathrm{v}$ ) at a flow rate of $1 \mathrm{ml} / \mathrm{min}$ with a Nova-Pak $\mathrm{C}_{18}$ column (3.9x150 mm, particle size $\left.4 \mu \mathrm{m}\right)$ (Waters Corporation, Milford, MA). The UV absorbance of eluents was monitored at $270 \mathrm{~nm}$. Calibration standards were prepared in blank rat plasma with concentrations ranging from 0.05 to $50 \mu \mathrm{g} / \mathrm{ml}$. The recovery of S-26 ranged from 95.1 to $99.6 \%$, as measured using low, medium and high concentration samples. The intra- and inter-day coefficients of variation of the assay were 5.2 and $8.5 \%$, respectively, at a concentration of $0.05 \mu \mathrm{g} / \mathrm{ml}$ (limit of quantitation, LOQ), and 2.4 and $0.22 \%$, respectively, at a concentration of $50 \mu \mathrm{g} / \mathrm{ml}$.

Pharmacokinetic data analysis and dose proportionality. The plasma concentration-time data were analyzed by both noncompartmental and compartmental methods using WinNonlin software (Pharsight Corporation, Mountain View, CA). WinNonlin was provided by a Pharsight Academic License to The Ohio State University. The terminal half-life $\left(\mathrm{T}_{1 / 2}\right)$ was calculated as $\mathrm{T}_{1 / 2}=0.693 / \lambda$, where $\lambda$ was the terminal disposition rate constant. The area under the plasma concentration-time curve $\left(\mathrm{AUC}_{0-\infty}\right)$ was calculated by the trapezoidal method with extrapolation to time infinity. The plasma clearance (CL) was calculated as $\mathrm{CL}=$ Dose $_{\text {i.v. }} / \mathrm{AUC}_{0-\infty \text { si.v. }}$, where Dose $\mathrm{i}_{\mathrm{i} . \mathrm{v} \text {. }}$ and $\mathrm{AUC}_{0-\infty}$, i.v. are the i.v. dose and the corresponding area under the plasma concentration-time curve from time zero to infinity, respectively. The apparent volume of distribution at 
equilibrium $\left(\mathrm{Vd}_{\mathrm{ss}}\right)$ was calculated as $\mathrm{Vd}_{\mathrm{ss}}=\mathrm{CL} \times \mathrm{MRT}$, where the MRT was the mean residence time following the intravenous bolus dose.

The pharmacokinetic parameter, $\mathrm{AUC}_{0-\infty}$ was utilized to assess dose proportionality of S-26 after i.v. dose of 1, 10 and $30 \mathrm{mg} / \mathrm{kg}$ by using the following power model (22): $Y_{i j}=$ $\alpha \times D^{\beta}{ }_{j} \times e_{i j}$, where $D_{j}$ is the dose at level $j ; Y_{i j}$ is the pharmacokinetic parameter for rat $i$ at dose level $j ; \alpha$ and $\beta$ are the mean intercept and slope, respectively; and $e_{i j}$ is the residual error for rat $i$ at dose level $j$. The model presented above can be transformed as $\ln \left(Y_{i j}\right)=\alpha+\beta \times \ln \left(D_{j}\right)+e_{i j}$, and fitted by using PROC MIXED procedure in SAS software (version 8.0; SAS Institute Inc., Cary, NC). A dose-proportional relationship is concluded if the $95 \%$ confidence interval of the estimated mean slope $(\beta)$ includes unity.

The mean concentration data under different doses were further simultaneously fitted by a two-compartment linear model:

$$
\begin{gathered}
V_{1} \frac{d C_{1}}{d t}=-C L \times C_{1}+C L_{d}\left(C_{2}-C_{1}\right) \\
V_{2} \frac{d C_{2}}{d t}=C L_{d}\left(C_{1}-C_{2}\right)
\end{gathered}
$$

where $V_{l}$ and $C_{l}$ are central compartment volume and concentration, $V_{2}$ and $C_{2}$ are peripheral compartment volume and concentration, and $C L_{d}$ represents intercompartment clearance. The weight is equal to $1 / \mathrm{Y}^{2}$. The goodness of fit was assessed by model convergence, visual inspection, precision of the parameter, Akaike Information Criteria (AIC), SCHWARZ (SC) and examination of the residuals.

Radiosynthesis of iodine-125 labeled $S-26$. The radioiodinated compound was prepared by oxidative iodination of the trimethyltin precursor (Fig. 1). Briefly, the reaction mixture consisted of $100 \mu \mathrm{l}$ of trimethyltin precursor solution $(25 \mu \mathrm{g} / \mathrm{ml}$ in ethanol), 0.5-1 mCi of $\mathrm{Na}^{125} \mathrm{I}$ in 5-10 $\mu \mathrm{l}$ of sodium hydroxide solution ( $\mathrm{pH} 10)$ and $0.1 \mathrm{ml}$ of freshly prepared Chloramine$\mathrm{T}(1 \mathrm{mg} / \mathrm{ml})$ in aqueous solution. The reaction was performed at room temperature for $15 \mathrm{~min}$, and was quenched by adding $0.2 \mathrm{ml}$ of aqueous sodium meta-bisulfate $(3 \mathrm{mg} / \mathrm{ml})$. The reaction mixture was then extracted with chloroform $(2 \times 2 \mathrm{ml})$. Radiolabeled S-26 was purified on a reversed phase Nova-Pak ${ }^{\circledR}$ $\mathrm{C}_{18}$ column by HPLC analysis. The overall yield ranged from $30-50 \%$, with at least $98 \%$ radiochemical purity obtained in all reactions. Specific activity of the final product ranged from 2130 to $2280 \mathrm{Ci} / \mathrm{mmol}$. The purified, radiolabeled S-26 was refrigerated $\left(4^{\circ} \mathrm{C}\right)$ and no degradation was observed for up to at least one week.

Biodistribution of radiolabeled S-26 in rats. Male SpragueDawley rats weighing about $250 \mathrm{~g}$ were used in these experiments. A single i.v. dose of $10 \mu \mathrm{Ci}$ of ${ }^{125}$ I-labeled S-26 was given to rats via the jugular vein. Dosing solutions were prepared in a vehicle containing 5\% DMSO (v/v) in PEG300. Intact male rats $(n=9)$ were divided into three groups and received an i.v. dose of ${ }^{125} \mathrm{I}$-labeled $\mathrm{S}-26$ (10 $\mu \mathrm{Ci}$ /animal) via the jugular vein. Animals were housed in individual metabolism cages with food and water provided ad libitum. Rats

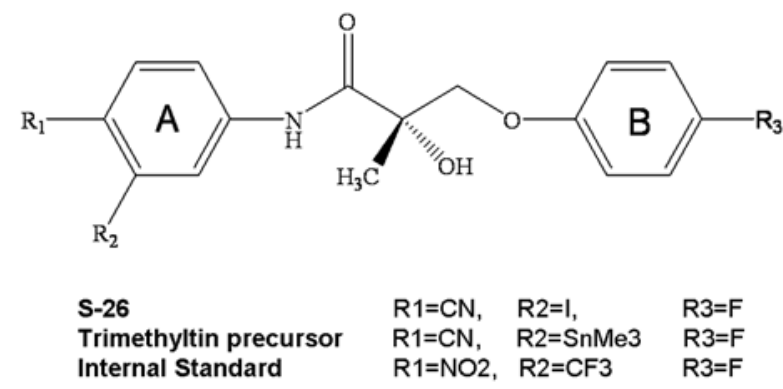

Figure 1. Chemical structure of S-26, S-26 trimethyltin precursor and internal standard. S-26, 3-(4-fluorophenoxy)-2-hydroxy-2-methyl-N-[4cyano-3-(iodide)phenyl]-propionamide.

Table Ia. Pharmacokinetic parameters of S-26 using noncom-

\begin{tabular}{|c|c|c|c|}
\hline Parameters & $1 \mathrm{mg} / \mathrm{kg}$ & $10 \mathrm{mg} / \mathrm{kg}$ & $30 \mathrm{mg} / \mathrm{kg}$ \\
\hline $\mathrm{T}_{1 / 2}(\mathrm{~h})$ & 4.07 & 4.08 & 3.89 \\
\hline $\operatorname{AUC}\left(\mu \mathrm{g}^{*} \mathrm{~h} / \mathrm{ml}\right)$ & $2.58 \pm 0.62$ & $32.35 \pm 2.00$ & $100.54 \pm 16.77$ \\
\hline $\operatorname{Vd}_{\mathrm{ss}}(1 / \mathrm{kg})$ & $1.82 \pm 0.13$ & $1.23 \pm 0.02$ & $1.28 \pm 0.16$ \\
\hline CL $(1 / \mathrm{h} / \mathrm{kg})$ & $0.38 \pm 0.10$ & $0.26 \pm 0.02$ & $0.26 \pm 0.04$ \\
\hline
\end{tabular}
partmental analysis.

Table Ib. Pharmacokinetic parameters of S-26 using twocompartmental analysis.

\begin{tabular}{lcc}
\hline Parameters & Estimate & $\mathrm{CV}$ \\
\hline $\mathrm{CL}\left(\mu \mathrm{g}^{*} \mathrm{~h} / \mathrm{l}\right)$ & 0.30 & 14.8 \\
$\mathrm{CL}_{\mathrm{d}}\left(\mu \mathrm{g}^{*} \mathrm{~h} / \mathrm{l}\right)$ & 0.60 & 1.8 \\
$\mathrm{~V}_{1}(1 / \mathrm{kg})$ & 0.84 & 4.6 \\
$\mathrm{~V}_{2}(1 / \mathrm{kg})$ & 0.78 & 6.4 \\
\hline
\end{tabular}

were sacrificed at 1,6 , or $18 \mathrm{~h}$ after drug administration. Blood, liver, kidney, lungs, heart, muscle, fat, prostate, seminal vesicle, epididymis, pancreas, spleen, brain, thyroid, urine and feces were collected, rinsed with saline, and blotted with paper. After weighing and mincing, the radioactivity in collected tissues were determined by means of gamma scintillation counting using a well counter. The uptake in each organ was expressed as percentage of injected dose per gram of tissue or blood $(\% \mathrm{ID} / \mathrm{g})$. The percentage of injected dose was determined by the comparison of the tissue radioactivity with suitably diluted aliquots of the injected dose.

Metabolism of S-26 in vivo. Urinary and fecal samples from rats were collected at $24 \mathrm{~h}$ intervals for up to $48 \mathrm{~h}$ after i.v. dosing and were stored at $-80^{\circ} \mathrm{C}$ until analysis. The animals were transferred to new cages at the end of each collection interval. Before analysis, urine samples were thawed and extracted with two volumes of ethyl acetate. The extraction procedure was repeated three times and the combined organic phase and the combined aqueous phase were evaporated separately to dryness. The residues were reconstituted in a 
Table II. Tissue biodistribution of ${ }^{125} \mathrm{I}$ S-26 at dose of $1 \mathrm{mg} / \mathrm{kg}$ in rats $(\mathrm{n}=3)$ expressed in percentage of injected dose/g of tissue.

\begin{tabular}{|c|c|c|c|}
\hline Tissue & $1 \mathrm{~h}$ & $6 \mathrm{~h}$ & $18 \mathrm{~h}$ \\
\hline Blood & $0.16 \pm 0.02$ & $0.15 \pm 0.02$ & $0.07 \pm 0.02$ \\
\hline Skin & $0.45 \pm 0.16$ & $0.19 \pm 0.03$ & $0.10 \pm 0.03$ \\
\hline Thyroid & $15.03 \pm 1.72$ & $29.85 \pm 8.99$ & $72.87 \pm 0.38$ \\
\hline Liver & $0.66 \pm 0.09$ & $0.47 \pm 0.04$ & $0.14 \pm 0.03$ \\
\hline Lung & $0.35 \pm 0.11$ & $0.18 \pm 0.01$ & $0.07 \pm 0.02$ \\
\hline Heart & $0.22 \pm 0.03$ & $0.11 \pm 0.01$ & $0.03 \pm 0.01$ \\
\hline Spleen & $0.18 \pm 0.02$ & $0.10 \pm 0.01$ & $0.05 \pm 0.03$ \\
\hline Kidney & $0.27 \pm 0.03$ & $0.20 \pm 0.04$ & $0.07 \pm 0.02$ \\
\hline Pancreas & $0.46 \pm 0.06$ & $0.16 \pm 0.02$ & $0.06 \pm 0.03$ \\
\hline Thymus & $0.15 \pm 0.01$ & $0.10 \pm 0.02$ & $0.03 \pm 0.01$ \\
\hline Brain & $0.10 \pm 0.04$ & $0.04 \pm 0.01$ & $0.01 \pm 0.00$ \\
\hline Prostate & $0.35 \pm 0.06$ & $0.21 \pm 0.06$ & $0.07 \pm 0.02$ \\
\hline Testis & $0.15 \pm 0.02$ & $0.09 \pm 0.01$ & $0.04 \pm 0.01$ \\
\hline Seminal vesicles & $0.11 \pm 0.02$ & $0.28 \pm 0.35$ & $0.07 \pm 0.01$ \\
\hline Fat & $0.83 \pm 0.63$ & $0.66 \pm 0.16$ & $0.09 \pm 0.03$ \\
\hline Muscle & $0.12 \pm 0.00$ & $0.07 \pm 0.01$ & $0.02 \pm 0.00$ \\
\hline Bladder & $0.41 \pm 0.16$ & $0.43 \pm 0.24$ & $0.28 \pm 0.17$ \\
\hline Stomach wall & $1.29 \pm 0.24$ & $0.73 \pm 0.28$ & $0.53 \pm 0.29$ \\
\hline Small intestines & $1.47 \pm 0.44$ & $0.58 \pm 0.23$ & $0.20 \pm 0.05$ \\
\hline SI contents & $2.27 \pm 0.61$ & $2.48 \pm 0.93$ & $0.42 \pm 0.12$ \\
\hline Large intestines & $0.35 \pm 0.13$ & $0.18 \pm 0.04$ & $0.38 \pm 0.50$ \\
\hline Urine & $0.87 \pm 0.22$ & $2.05 \pm 0.19$ & $1.90 \pm 0.14$ \\
\hline Feces & $0.05 \pm 0.04$ & $0.04 \pm 0.00$ & $8.42 \pm 4.24$ \\
\hline
\end{tabular}

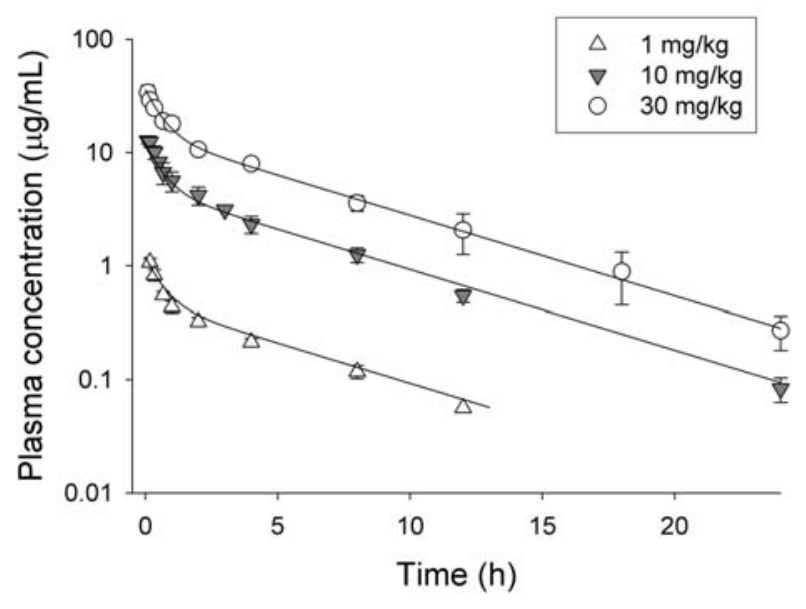

Figure 2. Plasma concentration-time profile of S-26 in rats with 3 different i.v. doses. Each point represents the mean $\pm \mathrm{SD}$ ( $\mathrm{n}=5 /$ group).

mobile phase of acetonitrile/ $\mathrm{H}_{2} \mathrm{O}[50: 50(\mathrm{v} / \mathrm{v})]$, and the solution was filtered through an Acrodisc syringe filter $(0.2 \mu \mathrm{m}, 13 \mathrm{~mm}$; Pall Corporation, East Hills, NY). The filtrate was applied to liquid chromatography tandem mass spectrometry (LC-MS/ MS) analyses as described below. Fecal samples were extracted three times with $10 \mathrm{ml}$ of a mixture of methanol/ethyl acetate $[2: 1(\mathrm{v} / \mathrm{v})]$. The liquid phase after each extraction was combined and evaporated. The resulting semisolid residues were then
Table III. Biodistribution of ${ }^{125}$ I S-26 in rats $(n=3)$, excretion and accumulation were expressed as percentage of dose.

\begin{tabular}{lcrr}
\hline$\%$ of dose & $1 \mathrm{~h}$ & $6 \mathrm{~h}$ & \multicolumn{1}{c}{$18 \mathrm{~h}$} \\
\hline Thyroid & $1.12 \pm 0.2$ & $2.23 \pm 0.7$ & $5.18 \pm 0.1$ \\
Urine excretion & $2.93 \pm 2.1$ & $10.07 \pm 2.0$ & $32.87 \pm 2.3$ \\
Feces excretion & $0.02 \pm 0.02$ & $0.03 \pm 0.02$ & $29.52 \pm 2.1$ \\
$\begin{array}{l}\text { Total recovery } \\
\text { of radioactivity }\end{array}$ & 84 & 60 & 83 \\
$(\%$ of dose $)$ & & & \\
\hline
\end{tabular}

well mixed with methanol and were filtered followed by LC-MS/MS analyses.

LC-MS/MS analysis. Mass spectrometric analyses were performed using a ThermoFinnigan LCQ DECA XP MAX ion trap mass spectrometer (San Jose, CA, USA) coupled with a Shimadzu (Kyoto, Japan) HPLC system consisting of an autosampler (SIL-20A) and a capillary binary pump (LC20AD) with on-line degasser. The autosampler was set at $4^{\circ} \mathrm{C}$ during analysis. Data acquisition was controlled by Xcalibur software. An aliquot $(10 \mu \mathrm{l})$ of each sample was injected into a C18 column (Beckman Coulter, Fullerton, CA, 250x2.0 mm, $5 \mu \mathrm{m}$ ) at a flow rate of $0.2 \mathrm{ml} / \mathrm{min}$ using a gradient mobile phase comprised of water (A) and acetonitrile (B). The mobile 
Table IV. Metabolites of S-26 identified in rat urine and feces within $24 \mathrm{~h}$ after i.v. dose.

Molecular ions (M-H)-

$439(\mathrm{~S}-26)$

$455(\mathrm{~S}-26+\mathrm{O})$

$327,299,243$

$535\left(\mathrm{~S}-26+\mathrm{O}+\mathrm{SO}_{3} \mathrm{H}\right)$

455,299

$313(\mathrm{~S}-26-\mathrm{I})$

$329(\mathrm{~S}-26+\mathrm{O}-\mathrm{I})$

$201,173,127$

$201,173,111$,

$409\left(\mathrm{~S}-26+\mathrm{O}-\mathrm{I}+\mathrm{SO}_{3} \mathrm{H}\right)$

329,173
Assigned structure and proposed fragmentation patterns
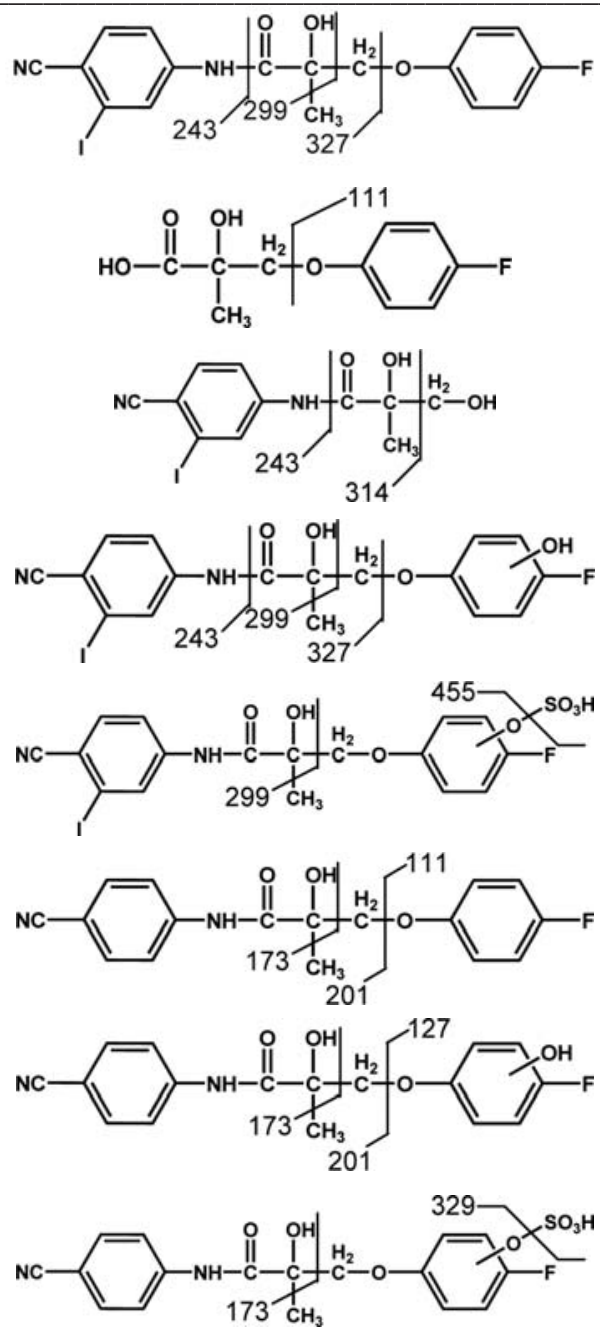

phase was comprised of $0 \% \mathrm{~B}$ for the first $5 \mathrm{~min}$ and the flow was diverted to waste, increased to $65 \% \mathrm{~B}$ in a linear gradient from 5 to $35 \mathrm{~min}$, and then further increased to $90 \%$ B from 35 to $36 \mathrm{~min}$ and maintained for $5 \mathrm{~min}$, and finally returned to $0 \% \mathrm{~B}$ at $42 \mathrm{~min}$. The column was equilibrated with the initial mobile phase for $10 \mathrm{~min}$. The mass spectrometer was tuned with S-26 and operated in the negative ion mode. The heated capillary temperature and spray voltage were set at $285^{\circ} \mathrm{C}$ and $5 \mathrm{kV}$, respectively. The sheath and auxiliary gas flow rates were 35 and $2 \mathrm{ml} / \mathrm{min}$, respectively. For MS/MS analysis, selected precursor ions were isolated with a width of $3 \mathrm{~m} / \mathrm{z}$ and fragmented with $38 \%$ of energy for negative ion mode.

Statistical analyses. The results (mean \pm SD) of all of the experiments were subjected to statistical analysis by one-way ANOVA. The level of significance was set at $\mathrm{P}<0.05$.

\section{Results}

Pharmacokinetic studies and dose proportionality. As a prelude to the biodistribution studies, we examined the pharmacokinetics of unlabeled S-26 in male, Sprague-Dawley rats in order to verify its in vivo stability and to determine the time frame needed for biodistribution studies with radiolabeled compound. The plasma concentration data were initially analyzed by non-compartmental analysis. The CL, $\mathrm{Vd}_{\mathrm{ss}}$, and $\mathrm{T}_{1 / 2}$ of S-26 did not vary significantly with dose ( $\mathrm{P}>0.05$ ) (Table Ia). The mean terminal half-life was $4.03 \mathrm{~h}$. The mean $( \pm \mathrm{SD}) \mathrm{CL}$ and $\mathrm{Vd}_{\mathrm{ss}}$ of S-26 were $0.30 \pm 0.07 \mathrm{l} / \mathrm{h} / \mathrm{kg}$ and $1.44 \pm 0.331 / \mathrm{kg}$, respectively. Dose proportionality of S-26 in rats was assessed by statistical analyses of log-transformed parameters and dose. The proportionality coefficient (ß) was estimated to be 1.12 , with a $95 \%$ confidence interval of 0.95-1.22. These data suggested that the pharmacokinetics of $\mathrm{S}-26$ in rats are dose independent.

The mean plasma concentration-time profiles of S-26 were further simultaneously described by a two-compartment model (Fig. 2). The CL, $\mathrm{Vd}_{\mathrm{ss}}\left(\mathrm{V}_{1}+\mathrm{V}_{2}\right)$ were estimated to be $0.30 \mathrm{l} / \mathrm{h} / \mathrm{kg}$ and $1.62 \mathrm{l} / \mathrm{kg}$ (Table Ib), which is correlated well to the results obtained from non-compartmental analysis (Table Ia).

Biodistribution studies. The concentration of ${ }^{125}$ I-labeled S-26 in each tissue and blood at 1, 6 and $18 \mathrm{~h}$ is presented in Table II. 
A
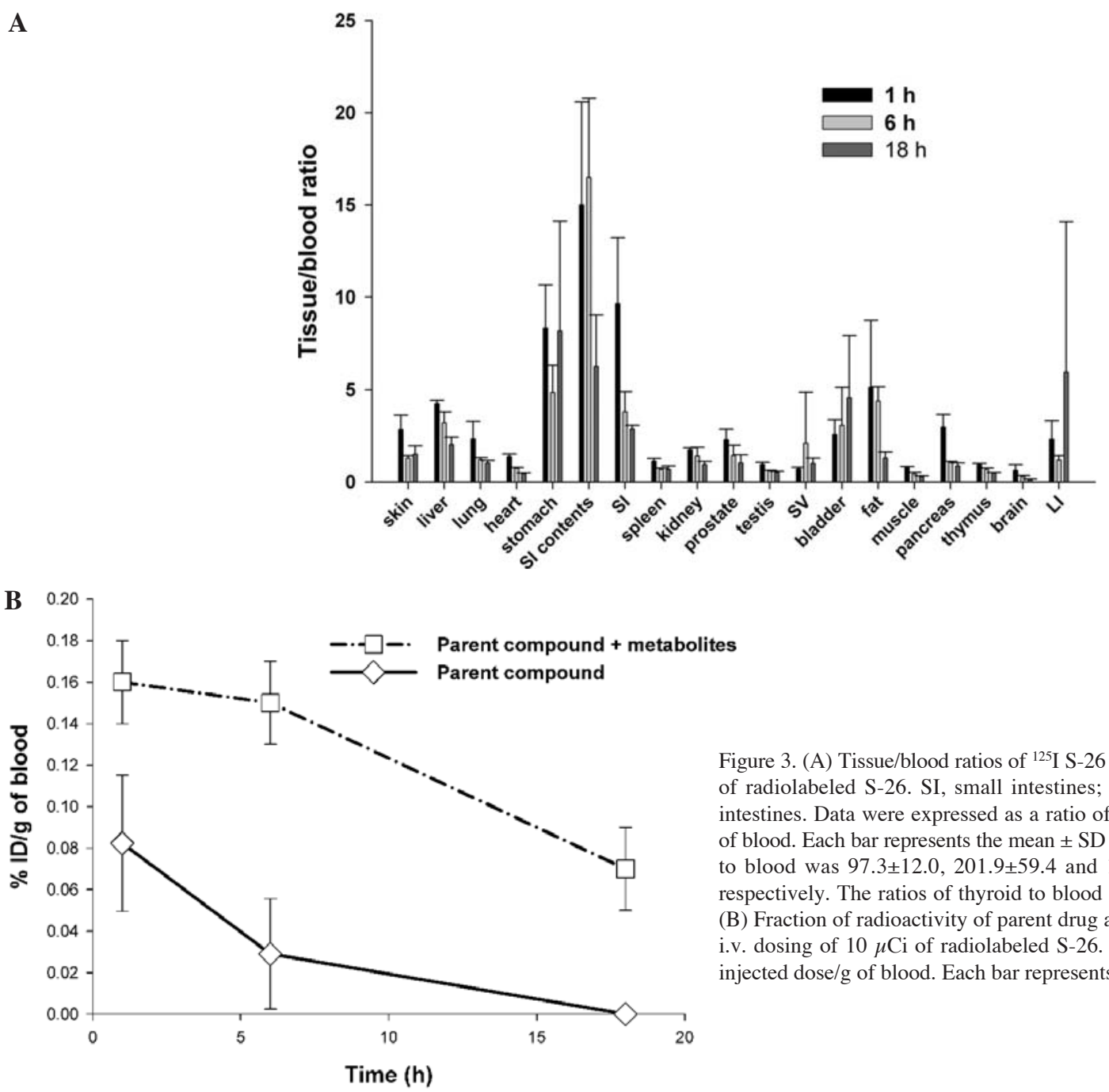

Figure 3. (A) Tissue/blood ratios of ${ }^{125} \mathrm{I} \mathrm{S}-26$ in rats after i.v. dosing of $10 \mu \mathrm{Ci}$ of radiolabeled S-26. SI, small intestines; SV, seminal vesicles; LI, large intestines. Data were expressed as a ratio of injected dose/g of tissue to that of blood. Each bar represents the mean $\pm \mathrm{SD}$ (n=3/group). The ratio of thyroid to blood was $97.3 \pm 12.0,201.9 \pm 59.4$ and $1219.9 \pm 60.6$ at 1,6 and $18 \mathrm{~h}$, respectively. The ratios of thyroid to blood were not included in this figure. (B) Fraction of radioactivity of parent drug and metabolites in rat blood after i.v. dosing of $10 \mu \mathrm{Ci}$ of radiolabeled S-26. Data are expressed as a ratio of injected dose/g of blood. Each bar represents the mean $\pm \mathrm{SD}$ ( $\mathrm{n}=3 /$ group).

At $1 \mathrm{~h}$ after i.v. administration of radiolabeled S-26, only a

Fig. 3A shows the ratio of radioactivity accumulated in tissue small percentage (less than $0.2 \%$ of the injected dose) was detected in blood, an observation that can be attributed to the large volume of distribution of the drug. The accumulation of radioactivity in the prostate gland (AR rich tissue) is of particular interest. Unfortunately, we did not observe appreciable radioactivity in $\mathrm{AR}$ rich tissues (i.e., prostate) as compared to other tissues (i.e., muscle, fat and blood). Radioactivity in the prostate represented only $0.35,0.21$ and $0.07 \% \mathrm{ID} / \mathrm{g}$ at 1,6 and $18 \mathrm{~h}$, respectively (Table II). The thyroid gland accumulated the greatest percentage of radioactivity in these studies (Table II). Within the first $6 \mathrm{~h}$, the major excretion pathway was through urine with 2.93 and $10.07 \%$ of the total radioactivity identified in samples collected during the 0-1 and 0-6 h periods, respectively (Table III). However, less than $0.1 \%$ of the total dose was recovered in fecal samples collected during the $0-6 \mathrm{~h}$ time period. During the period of $0-18 \mathrm{~h}$ after i.v. dosing, the percentage of radioactivity recovered in urine and feces were approximately equal (i.e., 32.9 and $29.5 \%$, respectively) (Table III). The large percentage of radioactivity found in urinary and fecal samples suggests that both urine and feces are major elimination pathways of S-26 and its metabolites. This was further confirmed by the large percentage of radioactivity found in intestinal tissue and intestinal contents during the first $6 \mathrm{~h}$ after dose administration (Table II). over that in blood. High ratios of tissue/blood were observed in GI tract, fat and bladder (Fig. 3A). Relatively large fractions of radiolabeled metabolites were found in blood after i.v. bolus of I-125-S-26 in rats (Fig. 3B).

Identification of major metabolites of S-26 in rat urine and feces. To identify and characterize the major metabolites of S-26 in rats, we collected both urinary and fecal samples from animals after i.v. dosing of S-26. These studies were conducted to provide information regarding the factor(s) that contributed to the failure of the targeting of radiolabeled S-26 to AR-rich tissues. Importantly, these studies on the metabolism of S-26 might also be useful for structural modification of non-steroidal ligands to the discovery of potential imaging agents. Metabolic profiles of S-26 in rat urinary and fecal samples were generated by electrospray ionization-mass spectrometry analysis. Blank urinary and fecal samples were also included in the analysis as a background control for the analysis of metabolites.

Our in vivo biodistribution using radiolabeled S-26 suggested that S-26 and its metabolites were eliminated from the body within $18 \mathrm{~h}$ after dose administration (Table III). Therefore, urinary and fecal samples from 0 to $24 \mathrm{~h}$ in rats were analyzed by LC/MS/MS. The $[\mathrm{M}-\mathrm{H}]^{-}$ion corresponding to the parent drug at $\mathrm{m} / \mathrm{z} 439$ and seven major metabolites 
A

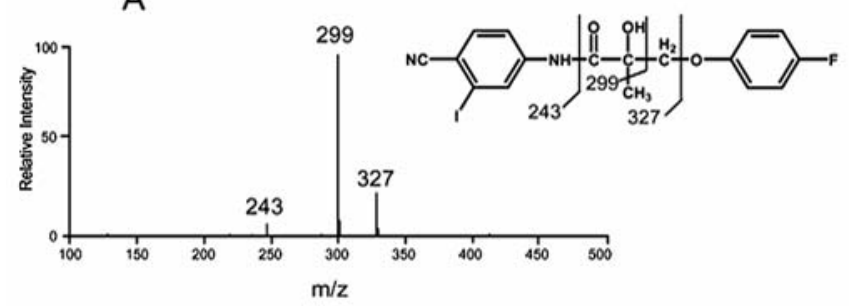

B

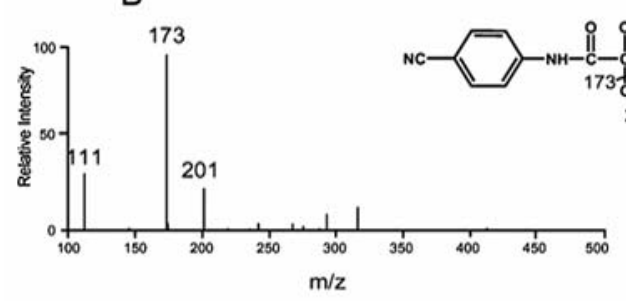

C
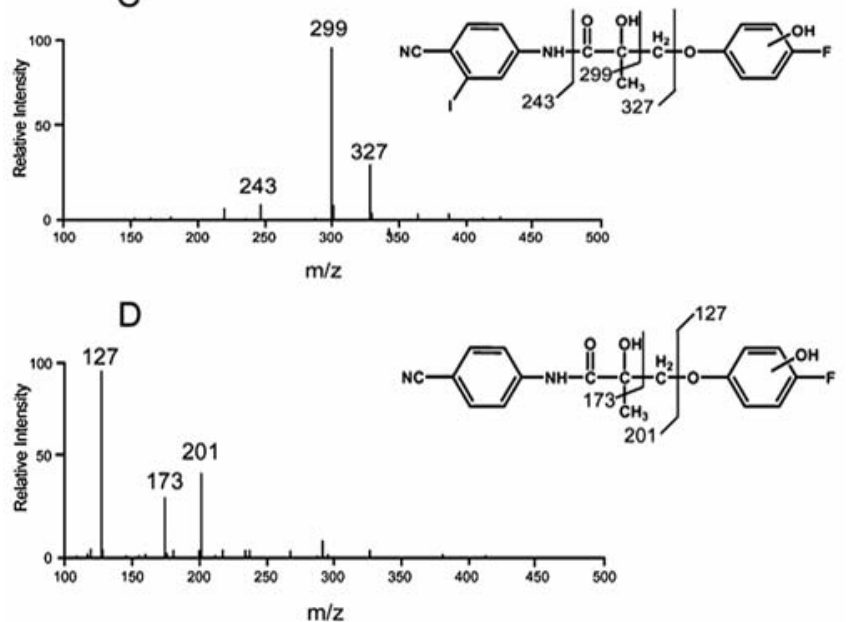

Figure 4. LC/MS/MS spectra of S-26 and major metabolites.

corresponding to $\mathrm{m} / \mathrm{z} 213,345,455,535,313,329$ and 409 were identified (Table IV). Parent compound (m/z 439), identified in both urine and feces, eluted at $37.0 \mathrm{~min}$ and yielded product ions of m/z 327, 299 and 243. Fig. 4A shows the proposed fragmentation ions of S-26. Similar metabolic pathways of SARMs were reported also previously by our laboratory (23-25). The product ion at $\mathrm{m} / \mathrm{z} 299$ corresponds to a cleavage of the bond between the chiral carbon and methylene carbon with loss of a methyl group. The product ion at $\mathrm{m} / \mathrm{z} 243$ likely resulted from a breakdown at the amide bond. Another fragmentation ion at $\mathrm{m} / \mathrm{z} 327$ was formed from the cleavage of the bond between the oxygen linker and B-ring. Two metabolic products from S-26 were also identified at $\mathrm{m} / \mathrm{z} 213$ and 345 (Table IV), which were exclusively found in urinary samples, not in feces. The $\mathrm{m} / \mathrm{z} 213$ ion was confirmed using a synthesized standard (with exactly the same HPLC retention time and identical [M-H] $]^{-}$and MS/MS pattern). The structure of $\mathrm{m} / \mathrm{z} 345$ was also confirmed using a synthesized analog (iodine in $\mathrm{A}$ ring was replaced by $\mathrm{CF}_{3}$ group). Their MS/MS spectra are shown in Fig. 5.

An oxidation (B-ring) product of S-26 and its subsequent sulfation product corresponded to the ions at $\mathrm{m} / \mathrm{z} 455$ and 535 (Table IV). The $\left[^{\mathrm{M}-\mathrm{H}}\right]^{-}$at $\mathrm{m} / \mathrm{z} 455$ (mono-hydroxylation of S-26) eluted at 31.2 and $32.8 \mathrm{~min}$ and yielded ions of $\mathrm{m} / \mathrm{z}$
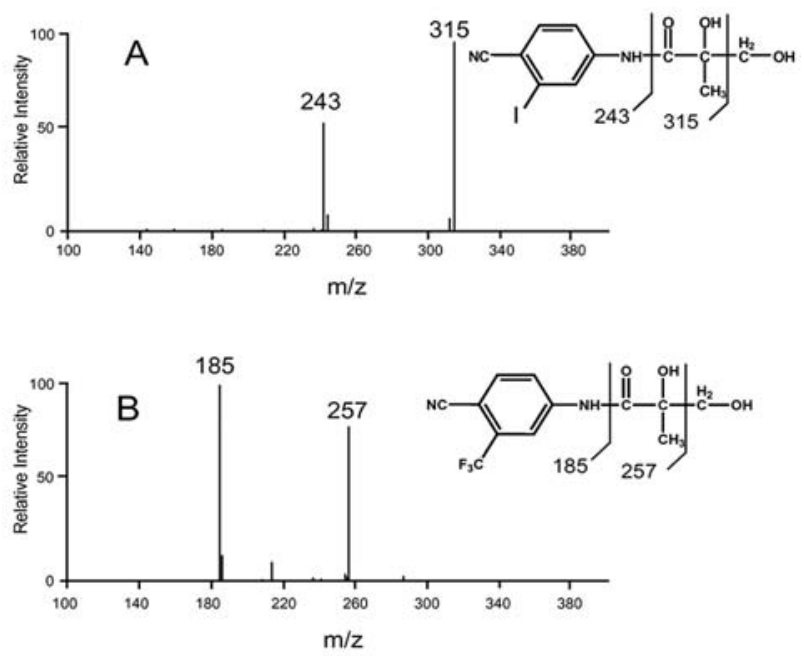

Figure 5. LC/MS/MS spectra of m/z 345 (A) was confirmed by a S-26 $\operatorname{analog}(\mathrm{B})$.

327,299 and 243 following exactly the same cleavage pattern of S-26 (Fig. 4C), suggesting that the B-ring might be the site of hydroxylation and that the oxidation happened at different positions. The MS/MS spectra of $\mathrm{m} / \mathrm{z}$ of 329 (de-iodinated $\mathrm{S}-26$ ) produced a fragment ion at $\mathrm{m} / \mathrm{z} 127$ (Fig. 4D), which further supports the idea that the B-ring was more susceptible to hydroxylation. The $[\mathrm{M}-\mathrm{H}]^{-}$at $\mathrm{m} / \mathrm{z} 535$ (sulfate conjugate in $\mathrm{B}$ ring) eluted at 20.2 and $21.1 \mathrm{~min}$ and yielded ions of $\mathrm{m} / \mathrm{z} 455$ (a cleavage of the sulfate group) and 299, further supporting the hypothesis that oxidation occurred at different $\mathrm{B}$ ring positions.

Loss of free iodine represents a very important metabolic pathway of S-26, as the free iodine will greatly contribute to its non-specific targeting and background radioactivity. The [M-H] $]^{-}$at $\mathrm{m} / \mathrm{z} 313$ (Table IV) was proposed to be the deiodinated S-26 and eluted at $33.5 \mathrm{~min}$. Fragmentation of this molecular ion produced ions at m/z 201, 173 and 111 (Fig. 4B). The cleavage pattern was similar to that of S-26. Further oxidation and subsequent sulfate conjugate of this deiodinated S-26 were identified at m/z 329 and 409 (Table IV).

The products of multiple hydroxylation and subsequent sulfation were found mainly in rat urine, with lesser amount in fecal samples (data not shown). This may be because these water soluble metabolites were mainly excreted via the kidneys, which is correlated with the results of in vivo biodistribution studies (where a high percentage of radioactivity was found in urinary samples at 1 and $6 \mathrm{~h}$ after dosing). In summary, S-26 was susceptible to three major phase I metabolic pathways; namely, deiodination, hydrolysis (at the amide bond), and oxidation (hydroxylation in B-ring). Sulfate conjugation was the major phase II metabolic pathway for S-26 in rats (Fig. 6).

\section{Discussion}

The biodistribution of a radioligand in animals can predict its usefulness as an imaging agent better than in vitro binding studies. Rats were selected for our biodistribution studies in that the mechanism of action of androgen in human prostate 


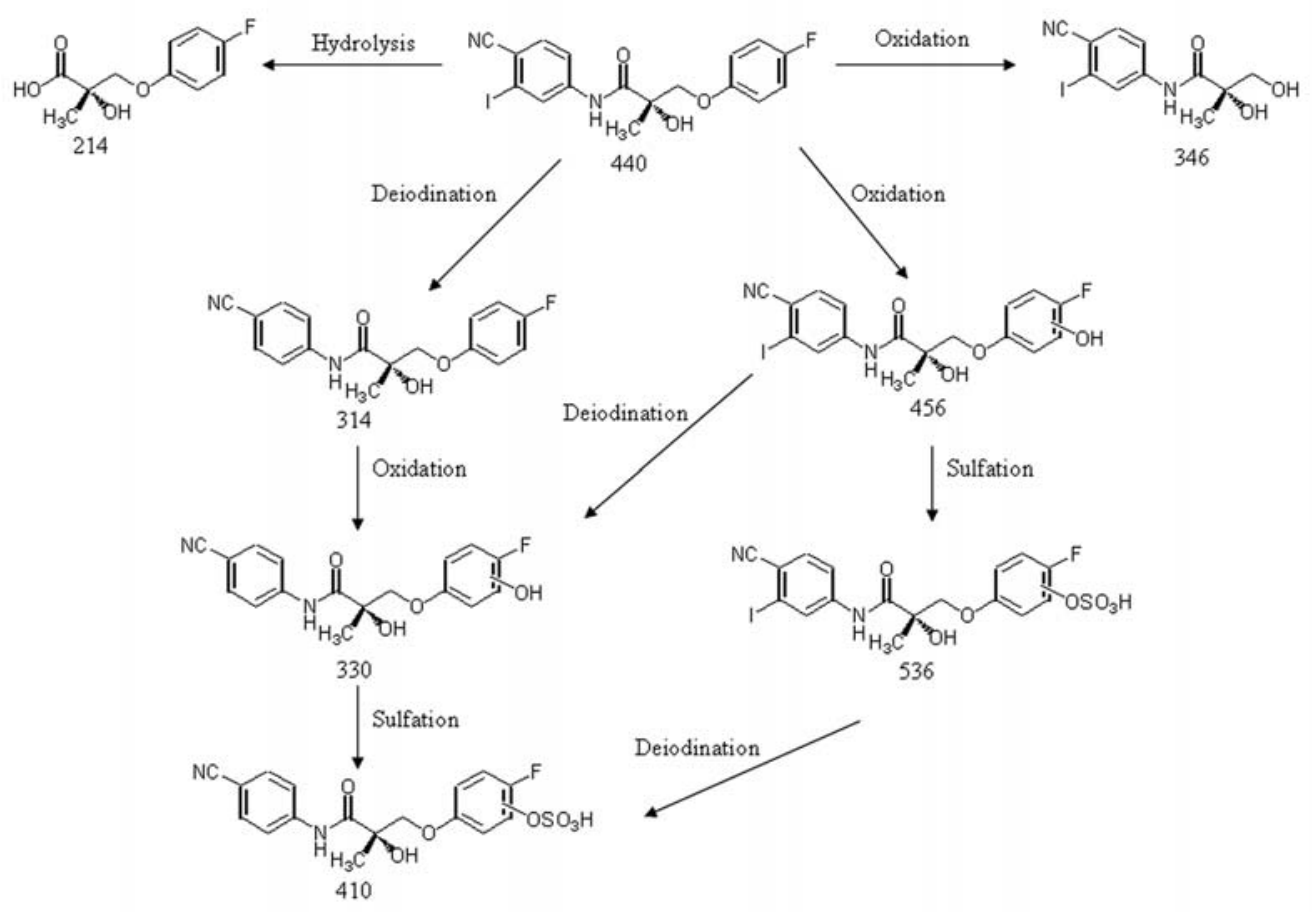

Figure 6. Proposed metabolism of S-26 in rats.

is similar to that in rat ventral prostate (26). In particular, the human AR has identical amino acid sequences in the DNA and ligand-binding domain to the rat AR $(27,28)$. However, the rat is not expected to be an ideal animal model for steroidal ligand imaging studies due to some inherent physiologic differences between man and rat. For example, rats do not express SHBG, which has a high binding affinity to steroids, while humans do $(29,30)$. Previous studies (18) show that non-steroidal ligands like S-26 do not bind to SHBG and other steroid receptors. Therefore, we expected that the rat would be a reasonable animal model for biodistribution studies of non-steroidal ligands.

Our pharmacokinetics studies with non-radiolabeled S-26 indicate that it has a half-life of about $4 \mathrm{~h}$. However, radioactivity detected in blood at $6 \mathrm{~h}$ was nearly identical to that observed at $1 \mathrm{~h}$ (i.e., 0.16 versus $0.15 \% \mathrm{ID} / \mathrm{g}$ ). This suggested that radiolabeled metabolites of S-26 or free iodine accumulated in the blood and represented a large fraction of the radioactivity present in these animals at later times.

High ratios of the drug concentrations in prostate (AR rich tissue) to blood and prostate to non-target tissues are required to obtain a promising imaging agent. Our in vivo biodistribution data demonstrate that radiolabeled S-26 was not selectively retained in the prostate. Among all tissues, the thyroid gland accumulated the highest percentage of radioactivity at all three time points, suggesting that S-26 was extensively de-iodinated in vivo, which was further confirmed by our metabolism studies using rat urine and feces. The deiodination of S-26 represented a different metabolic pathway of SARMs comparing to the metabolism studies previously reported by our laboratory (23-25). The high accumulation of radioactivity by GI tract and a large proportion of radioactivity in urine are also indications of release of free iodine from the parent drug in vivo. One possible explanation of such high uptake in thyroid and GI tract is that free iodine uptake is facilitated by sodium iodide symporter (NIS), an intrinsic plasma membrane protein which mediates the active transport of iodide presented in the thyroid gland, mammary gland, stomach and salivary gland $(31,32)$. Fat also represents a relatively high uptake of radioactivity in tissue, which might be due to the high lipophilicity (i.e., $\log \mathrm{P}=4.78$ ) of $\mathrm{S}-26$. However, it is important to note that rats appear to be unique in terms of their greater ability for amide bond cleavage of bicalutamide and the aryl propionamide SARMs as compared to dogs and humans (23-25,33). Therefore, rats may not represent an ideal model for the feasibility studies of radiolabeled SARMs. Additional studies to examine the pharmacokinetics and biodistribution of S-26 in dogs are ongoing in our laboratory.

It is well known that castration and treatment with diethylstilbestrol (DES) result in significant decreases in circulating concentrations of testosterone and DHT (34). To minimize the competitive binding from endogenous androgen, we further compared the biodistribution of ${ }^{125}$ I-labeled S-26 in intact rats to that observed in castrated rats and intact rats treated with DES in an attempt to clarify the role of AR mediated uptake in our studies. Although we found no favorable prostatic accumulation of radioactivity in either castrated or DEStreated rats (data not shown), we again found that the greatest accumulation of radioactivity occurred in the thyroid gland and the GI tract (i.e., stomach, small intestine and their contents). These studies corroborate our metabolism studies and provide further evidence that amide bond cleavage and de-iodination play an important role in the disposition of aryl propionamide SARMs in rats.

Our structure-activity studies on non-steroidal AR ligands showed that electron-withdrawing groups at the R2 (CN/ NO2) and R1 positions (CF3/I) (Fig.1) in the A-ring are essential to their binding affinity $(7,15)$. We found that, the biological half-life of non-steroidal ligands increased as the 
R3 substituent was modified from a fluoride to a chloride to a bromide to an iodide (Fig. 1) (35). Therefore, future studies with compounds incorporating iodine in the B-ring may provide a rational approach to the discovery of a novel agent for imaging of prostate cancer.

As a whole, in vivo studies of S-26 demonstrated that free iodine decomposition represented a significant fraction of the dose after i.v. administration of ${ }^{125}$ I-labeled S-26. Extensive metabolism of S-26 and accumulation of these metabolites in blood play a large role in explaining the poor specificity of radiolabeled S-26 in rat biodistribution studies. Our in vivo data with S-26 provided additional information suggesting that metabolically stable ligands with less lipophilicity and higher AR binding affinity represent a promising and rational approach for AR-mediated imaging. Additional studies with metabolically stable ligands and other animal models are warranted to further define the physiologic, metabolic and physiochemical factors important for AR-mediated imaging with non-steroidal ligands.

\section{Acknowledgements}

These studies were supported by grants from Department of Defense, US Army Prostate Cancer Research Program (Grant no. PC-001480).

\section{References}

1. Cancer Facts and Figures 2005. 2005 [cited 2009 Sept 15] Available from: http://www.cancer.org/downloads/STT/ CAFF2005f4PWSecured.pdf

2. Van der Kwast TH and Tetu B: Androgen receptors in untreated and treated prostatic intraepithelial neoplasia. Eur Urol 30: 265-268, 1996.

3. Sadi MV, Walsh PC and Barrack ER: Immunohistochemical study of androgen receptors in metastatic prostate cancer Comparison of receptor content and response to hormonal therapy. Cancer 67: 3057-3064, 1991.

4. Tilley WD, Lim-Tio SS, Horsfall DJ, Aspinall JO, Marshall VR and Skinner JM: Detection of discrete androgen receptor epitopes in prostate cancer by immunostaining: measurement by color video image analysis. Cancer Res 54: 4096-4102, 1994.

5. Hobisch A, Culig Z, Radmayr C, Bartsch G, Klocker H and Hittmair A: Distant metastases from prostatic carcinoma express androgen receptor protein. Cancer Res 55: 3068-3072, 1995.

6. Hobisch A, Culig Z, Radmayr C, Bartsch G, Klocker H and Hittmair A: Androgen receptor status of lymph node metastases from prostate cancer. Prostate 28: 129-135, 1996.

7. Kirkovsky L, Mukherjee A, Yin D, Dalton JT and Miller DD: Chiral nonsteroidal affinity ligands for the androgen receptor. 1 . Bicalutamide analogues bearing electrophilic groups in the B aromatic ring. J Med Chem 43: 581-590, 2000.

8. Yin D, He Y, Perera MA, Hong SS, Marhefka C, Stourman N, Kirkovsky L, Miller DD and Dalton JT: Key structural features of nonsteroidal ligands for binding and activation of the androgen receptor. Mol Pharmacol 63: 211-223, 2003.

9. Chen J, Hwang DJ, Bohl CE, Miller DD and Dalton JT: A selective androgen receptor modulator for hormonal male contraception. J Pharmacol Exp Ther 312: 546-553, 2005.

10. Gao W, Kearbey JD, Nair VA, Chung K, Parlow AF, Miller DD and Dalton JT: Comparison of the pharmacological effects of a novel selective androgen receptor modulator, the 5alpha-reductase inhibitor finasteride, and the antiandrogen hydroxyflutamide in intact rats: new approach for benign prostate hyperplasia. Endocrinology 145: 5420-5428, 2004.

11. Kearbey JD, Wu D, Gao W, Miller DD and Dalton JT: Pharmacokinetics of S-3-(4-acetylamino-phenoxy)-2-hydroxy-2-methyl$\mathrm{N}$-(4-nitro-3-trifluoromethyl-phenyl)-propionamide in rats, a non-steroidal selective androgen receptor modulator. Xenobiotica 34: 273-280, 2004
12. Yin D, Gao W, Kearbey JD, Xu H, Chung K, He Y, Marhefka CA, Veverka KA, Miller DD and Dalton JT: Pharmacodynamics of selective androgen receptor modulators. J Pharmacol Exp Ther 304: 1334-1340, 2003.

13. Yin D, Xu H, He Y, Kirkovsky LI, Miller DD and Dalton JT: Pharmacology, pharmacokinetics, and metabolism of acetothiolutamide, a novel nonsteroidal agonist for the androgen receptor. J Pharmacol Exp Ther 304: 1323-1333, 2003.

14. Chen J, Hwang DJ, Chung K, Bohl CE, Fisher SJ, Miller DD and Dalton JT: In vitro and in vivo structure-activity relationships of novel androgen receptor ligands with multiple substituents in the B-ring. Endocrinology 146: 5444-5454, 2005.

15. Dalton JT, Mukherjee A, Zhu Z, Kirkovsky L and Miller DD: Discovery of nonsteroidal androgens. Biochem Biophys Res Commun 244: 1-4, 1998.

16. Gao W, Reiser PJ, Coss CC, Phelps MA, Kearbey JD, Miller DD and Dalton JT: Selective androgen receptor modulator treatment improves muscle strength and body composition and prevents bone loss in orchidectomized rats. Endocrinology 146: 4887-4897, 2005.

17. Marhefka CA, Gao W, Chung K, Kim J, He Y, Yin D, Bohl C, Dalton JT and Miller DD: Design, synthesis, and biological characterization of metabolically stable selective androgen receptor modulators. J Med Chem 47: 993-998, 2004.

18. Yang J, Bohl CE, Nair VA, Mustafa SM, Hong SS, Miller DD and Dalton JT: Preclinical pharmacology of a nonsteroidal ligand for androgen receptor-mediated imaging of prostate cancer. J Pharmacol Exp Ther 317: 402-408, 2006.

19. Bohl CE, Chang C, Mohler ML, Chen J, Miller DD, Swaan PW and Dalton JT: A ligand-based approach to identify quantitative structure-activity relationships for the androgen receptor. J Med Chem 47: 3765-3776, 2004.

20. Nair VA, Mustafa SM, Mohler ML, Fisher SJ, Dalton JT and Miller DD: Synthesis of novel iodo derived bicalutamide analogs. Tetrahedron Lett 45: 9475-9477, 2004.

21. Nair VA, Mustafa SM, Mohler ML, Yang J, Kirkovsky LI, Dalton JT and Miller DD: Synthesis of irreversibly binding bicalutamide analogs for imaging studies. Tetrahedron Lett 46: 4821-4823, 2005.

22. Smith BP, Vandenhende FR, DeSante KA, Farid NA, Welch PA, Callaghan JT and Forgue ST: Confidence interval criteria for assessment of dose proportionality. Pharm Res 17: 1278-1283, 2000.

23. Gao W, Wu Z, Bohl CE, Yang J, Miller DD and Dalton JT: Characterization of the in vitro metabolism of selective androgen receptor modulator using human, rat, and dog liver enzyme preparations. Drug Metab Dispos 34: 243-253, 2006.

24. Wu D, Wu Z, Yang J, Nair VA, Miller DD and Dalton JT: Pharmacokinetics and metabolism of a selective androgen receptor modulator in rats: implication of molecular properties and intensive metabolic profile to investigate ideal pharmacokinetic characteristics of a propanamide in preclinical study. Drug Metab Dispos 34: 483-494, 2006.

25. Perera MA, Yin D, Wu D, Chan KK, Miller DD and Dalton JT: In vivo metabolism and final disposition of a novel nonsteroidal androgen in rats and dogs. Drug Metab Dispos, 2006.

26. Siiteri PK and Wilson JD: Dihydrotestosterone in prostatic hypertrophy. I. The formation and content of dihydrotestosterone in the hypertrophic prostate of man. J Clin Invest 49: 1737-1745, 1970.

27. Lubahn DB, Joseph DR, Sar M, Tan J, Higgs HN, Larson RE, French FS and Wilson EM: The human androgen receptor: complementary deoxyribonucleic acid cloning, sequence analysis and gene expression in prostate. Mol Endocrinol 2: 1265-1275, 1988.

28. Sack JS, Kish KF, Wang C, Attar RM, Kiefer SE, An Y, Wu GY, Scheffler JE, Salvati ME, Krystek SR Jr, Weinmann R and Einspahr HM: Crystallographic structures of the ligand-binding domains of the androgen receptor and its T877 A mutant complexed with the natural agonist dihydrotestosterone. Proc Natl Acad Sci USA 98: 4904-4909, 2001.

29. Mainwaring WI and Milroy EJ: Characterization of the specific androgen receptors in the human prostate gland. J Endocrinol 57: 371-384, 1973.

30. Murthy LR, Johnson MP, Rowley DR, Young CY, Scardino PT and Tindall DJ: Characterization of steroid receptors in human prostate using mibolerone. Prostate 8: 241-253, 1986.

31. Josefsson M, Grunditz T, Ohlsson T and Ekblad E: Sodium/ iodide-symporter: distribution in different mammals and role in entero-thyroid circulation of iodide. Acta Physiol Scand 175: 129-137, 2002 
32. Zuckier LS, Dohan O, Li Y, Chang CJ, Carrasco N and Dadachova E: Kinetics of perrhenate uptake and comparative biodistribution of perrhenate, pertechnetate, and iodide by $\mathrm{NaI}$ symporter-expressing tissues in vivo. J Nucl Med 45: 500-507, 2004.

33. Boyle GW, McKillop D, Phillips PJ, Harding JR, Pickford R and McCormick AD: Metabolism of casodex in laboratory animals. Xenobiotica 23: 781-798, 1993.

34. Scherr DS and Pitts WR Jr: The nonsteroidal effects of diethylstilbestrol: the rationale for androgen deprivation therapy without estrogen deprivation in the treatment of prostate cancer. J Urol 170: 1703-1708, 2003.

35. Kim J, Wu D, Hwang DJ, Miller DD and Dalton JT: The para substituent of S-3-(phenoxy)-2-hydroxy-2-methyl-N-(4-nitro-3trifluoromethyl-phenyl)-prop ionamides is a major structural determinant of in vivo disposition and activity of selective androgen receptor modulators. J Pharmacol Exp Ther 315: 230-239, 2005. 